\title{
Clean people, unclean people: the essentialisation of 'slaves' among the southern Betsileo of Madagascar
}

\begin{abstract}
In this article I argue that among the southern Betsileo slave descendants are essentialised by free descendants. After explaining how this striking case of psychological essentialism manifests in the local context, I provide experimental evidence for it and discuss the results of three cognitive tasks that I ran in the field. I then suggest that slaves were not essentialised in the pre-colonial era and contend that the essentialist construal only became entrenched in the aftermath of the 1896 abolition of slavery, which paradoxically triggered the historical process of essentialisation.
\end{abstract}

Key words psychological essentialism, slavery, uncleanliness, cognition, abolition, Madagascar

\section{Introduction}

In the southern Betsileo highlands of Madagascar, a sharp distinction is drawn between clean and unclean people. The expression 'clean people' (olo madio) refers to persons who are said to have free ancestry, whereas 'unclean people' (olo tsy madio) is used to label those who are considered to have slave forebears. This distinction pervades southern Betsileo social life and is far from being benign: on the grounds of their alleged uncleanliness and inferior status, slave descendants are discriminated 'in a thousand encounters in everyday life' (Kottak 1980: 104), despite the fact that free and slave descendants often perform the same activities, live in the same villages, go to the same schools and churches, and sometimes have excellent relationships with each other.

During the two-year fieldwork I conducted in Beparasy, a rural area of the southern Betsileo region, I dedicated a large amount of time to understanding the condition of slave descendants. My approach to the problem was of course much influenced by the specific situation I discovered in the field. Soon after my arrival in Beparasy, I became acquainted with members of a local descent group called the Berosaiña. ${ }^{1}$ Initially, I did not know that they had a reputation of slave descent, but as time went on I discovered that the Berosaiña were considered to be unclean people, even though they were a well-established group owning land, cattle and ancestral tombs.

I found the situation of the Berosaiña striking since my readings of the ethnographic literature had given me the idea that Betsileo slave descendants lived a rather miserable life, either in poor satellite hamlets where they sharecropped the land of their former masters - as in the cases described by Kottak (1980) and Freeman (2013) - or in migrant villages where they were harshly treated and exploited because they were not able to prove a clean ancestry - as reported by Evers (2002). In comparison, the

1 Beparasy and Berosaiña are fictitious names that I use to preserve the anonymity of my informants. 
Berosaiña were well integrated in the local peasant community and, to a certain extent, treated as equals. I eventually found out that this relative integration was in most part due to the fact that one of their ancestors was among the first settlers of Beparasy. I therefore wondered: if their social and economic condition is rather fortunate compared with that of other slave descendants in the region, why have the Berosaina remained locked in such an unclean and low status?

The short answer is that the Berosaiña are stuck in this situation because free descendants strictly refuse to marry them. The Berosaina, in consequence, have no other option than marrying other slave descendants, and these alliances with people who are themselves considered unclean further strengthen the prejudice of free descendants against them. This answer, however correct, begs the question: why do free descendants refuse so strictly to marry slave descendants? Elsewhere I have provided an account of the different reasons for the marriage avoidance, highlighting in particular status-isogamous marriage rules, the vigilant memory of 'origins' and a principle of hypodescent applied in case of mixed marriages (Regnier 2014b). To account for the way free descent people think of the Berosaiña, I also suggested that they strongly essentialise slave descendants, using the term 'essentialise' in the specific sense of psychological essentialism. To put it simply, I argued that free descendants think of slave descendants as having an inner essence that makes them what they are and that cannot be changed.

My goal in this article is to examine more closely the essentialist construal of 'slaves' (andevo) among the southern Betsileo by combining ethnographic observations, cognitive experiments and historical analysis. In the first part, I will explain why I think that slave descendants are essentialised. To this aim, I will provide ethnographic details on how free descendants think of the Berosaiña in Beparasy and discuss the results of an experimental study I conducted in the field. In the second part, I will argue that 'slaves' in pre-abolition times were probably not essentialised as they are today, and suggest a speculative account of the historical events that led to the essentialism that now prevails.

\section{'Slaves' (andevo) among the southern Betsileo}

Most of the southern Betsileo are rice-growing and cattle-raising peasants who live in rural villages and hamlets close to their rice fields, in the meridional part of the central highlands of Madagascar. The basic units of their social organisation are the tombcentred, named local descent groups (foko; firazanana). Membership of these groups is cognatic, optative and non-exclusive, but shows a strong patrilineal bias since most people prefer viri-patrilocal post-marital residence and they are most often buried in their father's tomb (Kottak 1980), even though they have the right to be buried in any of the tombs of the descent groups to which they belong. Ancient southern Betsileo society was very hierarchical and made up of three endogamous status groups: 'nobles' (hova), 'commoners' (olompotsy, sometimes also called vohitse) and 'slaves' (andevo). This division of all southern Betsileo into three categories continues to be relevant up to this date.

The relevance of these caste-like status groups, called raza, is particularly obvious when it comes to understanding the situation of the 'slaves' (andevo) today. ${ }^{2}$ In

2 Among the southern Betsileo 'slave' (andevo) is used as shorthand for 'slave descendant' (taranak'andevo or dorian'andevo). It does not refer to contemporary forms of slavery, which to my knowledge do not exist in the usual sense of the term in the region. 
Beparasy I was frequently told by the olompotsy, who represent the vast majority of the southern Betsileo population, 'nowadays everyone is like everyone else' (efa mitovy aby am'izao). This statement was meant to stress the equality of (economic) conditions between the olompotsy and the andevo who live among them. ${ }^{3}$ Yet, the olompotsy were also quick to clarify that it is strictly forbidden for them to marry the andevo. The issue of marriage, my informants often added, is their only problem with the andevo. A number of sociological and historical reasons account for the olompotsy's reluctance to marry slave descendants but one of the most striking aspects of the problem is the fact that the olompotsy call them olo tsy madio ('unclean people', or olo maloto, 'dirty people') and consider their uncleanliness to be polluting. A number of euphemisms are also used to refer to slave descendants but olo tsy madio and olo maloto are by far the most commonly employed terms.

Whereas a minority of my olompotsy informants explained they would be polluted (and could become sick) if they shared a plate or a glass with an andevo, most of them considered that it is only through intimate and regular contacts that this can happen. People often illustrated the issue of pollution by referring to the case of 'mixed' unions, i.e. olompotsy-andevo couples setting up a 'hearth in a house' (tokantrano) together in spite of the prohibition. It must be clear that the prohibition only comes from the side of the olompotsy, because andevo families never prevent their members from marrying olompotsy. Actual cases of 'mixed' unions are not very frequent but during my fieldwork I encountered three (Regnier 2012: chapter 5). In such cases, olomposty families repudiate their members who have breached the prohibition and exclude them from the ancestral tomb. This exclusion is arguably the most serious social sanction for the southern Betsileo. Moreover, to the eyes of their olompotsy relatives, the excluded members have become unclean through the sexual contacts with their andevo partner. Consequently, if they want to be buried in the ancestral tomb - for example, if their union breaks up and they go back to their family asking for forgiveness - they will have to be cleansed through a costly ritual involving the killing of an ox.

The problem becomes even more sensitive if the mixed couple produce children. In that case, the couple's children are also considered to be unclean by the olompotsy side, but unlike their olompotsy parent the children cannot be cleansed through a ritual because their olompotsy relatives view them as irredeemably unclean. From the olompotsy's point of view, therefore, the couple's unclean children can only be buried in andevo tombs or, alternatively, in a separate tomb that the olompotsy build for them. ${ }^{4}$ The olompotsy thus seem to think that andevo parents inevitably transmit their uncleanliness to their children. ${ }^{5}$

When I asked my olompotsy informants why the andevo were unclean, they explained that slaves in the past had to deal with 'dirt' (ny maloto) all the time. When asked what kind of dirt, they almost unanimously stressed the daily handling of

3 Kottak, who carried out research in the 1960s, estimated the proportion of people called 'slaves' (andevo) in the southern Betsileo population varied between 5\% and 15\% (1980: 105). This estimate is consistent with my own observations. It is important to note, however, that many andevo live in mixed villages (i.e. with olompotsy and sometimes hova families).

4 The building of a new, separate tomb to solve the problem of unclean children was often mentioned to me as the only acceptable solution, because olompotsy are very reluctant to 'abandon' the children to the andevo and their tombs. In practice, however, such a solution is costly and generates further problems in the olompotsy descent group, in particular because it damages its reputation.

5 This is a case of hypodescent (Harris and Kottak 1963) because the children are automatically ascribed the status of the 'inferior' parent. 
excrements (tay) and other soiling tasks such as cleaning the cattle pen. Some explained that the blood $(r \grave{a})$ of slave descendants had become unclean through their frequent contact with dirt. ${ }^{6}$

My olompotsy informants thus seemed to consider that andevo have something that cannot be observed directly, but that makes them intrinsically unclean and permanently bestows on them the identity of unclean people. ${ }^{7}$ Their uncleanliness conceptualised either vaguely or somewhat more precisely in terms of unclean blood - seems to be conceived by the olompotsy as if it were lodged 'deep inside' them. Moreover, as I have already explained, the olompotsy hold that the uncleanliness transmitted by the andevo parent to the children of mixed unions is impossible to cleanse. All this seems to bear a clear signature of psychological essentialism.

According to Medin, who first coined the term, psychological essentialism refers to the tendency to 'act as if things (...) have essences (...) that make them the things they are’ (1989: 1476). A growing body of research has provided evidence of its pervasiveness as a cognitive bias, including in very young infants (Gelman 2003) and across cultures (e.g. Atran 1998; Mahalingam 1998; Astuti et al. 2004). Yet not all 'things' are essentialised and scholars are still debating why some are more readily essentialised than others.

Since psychological essentialism appears to be particularly frequent in social categorisation it has attracted the attention of social psychologists (see in particular the contributions in Yzerbyt et al. 2004) and, more rarely, anthropologists. In social psychology it has been investigated in a variety of domains including gender, religion, sexual orientation and political groups (Prentice and Miller 2007), while in anthropology it has been notably discussed in relation to racism (Hirschfeld 1996), ethnicity (Gil-White 2001) and language (McIntosh 2005).

In a seminal article, Rothbart and Taylor suggested that 'whereas social categories are in reality more like human artifacts than natural kinds, they are often perceived as more like natural kinds than human artifacts' (1992: 12) and like natural kinds they are often assumed to have an underlying essence. This line of research linking essentialism and natural kind-ness has been widely followed in social psychology, whereas others (e.g. Yzerbyt et al. 2001) have examined the relations between essentialism and entitativity (i.e. the perception of a strong degree of similarity and organisation among the members of a group). More recently, however, some scholars have argued that essentialism about social categories should be strictly differentiated from natural kind-ness and entitativity, and restricted to the attribution of an underlying essence to social groups (Demoulin et al. 2006). For these authors, what matters is whether groups are perceived as 'forced social categories', i.e. categories whose membership is imposed on people, or 'chosen social categories', i.e. categories whose membership is dependent on group members' personal choice. According to them, both categories can be equally essentialised, but forced social categories are essentialised because they are perceived as highly 'natural' groups, whereas chosen social categories are essentialised because they are perceived as highly entitative.

6 Evers also reports that her informants viewed the uncleanliness of slave descendants as an uncleanliness of blood (2002: 70).

7 In other regions of Madagascar, such as in Imerina, slave ancestry is often suspected or ascribed on the basis of phenotype (Razafindralambo 2014). This is not the case among the southern Betsileo. 
Slave descendants in the southern Betsileo region are clearly perceived as a forced social category by the olompotsy, who are very well aware that this inferior status is not the slave descendants' choice and that this identity is imposed on them. Moreover the slave descendants' forced endogamy - a consequence of the fact the olompotsy strictly refuse to marry them - strengthens the perception that they are 'a different kind of people' (karaza olo hafa) and a 'natural' category.

\section{Has this person become clean? A short experimental study}

In order to explore the issue of whether olompotsy essentialise slave descendants, I conducted a field experiment in Beparasy from September to October 2012 and in April 2013. It consisted in telling people three stories about an adoption, a cleansing ritual and a blood transfusion that focused on either an unclean or a clean fictional character (see annexes). These stories were followed by the following question: 'In your opinion, has this person become clean [or unclean] or has s/he remained unclean [clean]?' The tasks were designed in such a way that the stories sound familiar, and the question seems relevant and easily understandable. The question was followed by an open conversation during which I asked people to explain their answer. ${ }^{8}$ Each of the tasks found their rationale in issues that arose from my long-term participant observation fieldwork in Beparasy.

The idea of using an adoption task came to my mind while I was in the field, after I had heard about a kind of 'natural experiment' bearing much resemblance with adoption stories used in cognitive psychology. It concerned two villagers who had arrived in Beparasy as babies in the 1960s. As I was told, a man from the eastern coast had proposed the babies for adoption because they were twins. Twins are thought to bring bad luck among some populations of the east coast of Madagascar and are therefore often abandoned by their parents. A childless couple of Beparasy decided to take these two babies to raise them as their children. In 2008-10, the twins were about 50 years old. A member of the local descent group of the twins' adoptive father told me that there had been on-going discussions within his family about whether the twins could be buried in the ancestral tomb. When I first heard the story, I thought that these difficulties had to do with the reputation of bad luck attached to twins, but I was told that the Betsileo do not believe that twins bring bad luck. The problem was of a different nature: at stake was the fact that nobody knew the origins (fiavy) of the twins and what their status group (raza) might be. The fear, I was told, was that they might be unclean persons, i.e. 'slaves'. The matter was not yet settled at the time of my last visit - indeed, it will be definitely settled only at the time of the twins' death - but in the family the prevailing opinion was that the twins, as well as their children, should be buried outside of the ancestral tomb as a precaution.

Adoption and fosterage are very frequent practices in Madagascar, which reflect the 'fluidity' and 'optativity' often attributed to Malagasy kinship in general (Southall

8 Unfortunately, due to a lack of space I cannot do justice to the ethnographic richness of these conversations, which were remarkably open in comparison with more ordinary contexts where a 'silence' on slavery is usually observed (Somda 2009; Freeman 2013). Retrospectively, running the three tasks proved a very effective way to circumvent the southern Betsileo reticence to talk about slavery and slave descent. 
1986; Kottak 1986). A person's affiliation with a particular kin group and social identity is not fixed at birth but changes throughout life; it is only fixed at the time of death, when this person is placed in an ancestral tomb (Bloch 1993). Adoption and switchedat-birth tasks have already been used in Madagascar to explore issues of biological inheritance among Zafimaniry (Bloch et al. 2001) and Vezo adults and children (Astuti et al. 2004). My aim was to use an adoption scenario to explore essentialism since I thought that if olompotsy had an essentialist view they would hold, contrary to ideas of fluid social identity, that a baby of slave descent adopted and raised by a free descent family would not become a clean person in adulthood. On the basis of the real-life story about the twins, I expected that a number of olompotsy would provide such a negative answer, although the fact that there was an on-going discussion within the twins' adoptive family indicated some degree of disagreement. The adoption task's main goal was thus to get an idea of the proportion of respondents who would hold an essentialist view.

The cleansing ritual task had a similar goal. As I have explained above, the children of mixed olompotsy-andevo couples are considered by the olompotsy side to be irredeemably unclean; for this reason, they cannot be buried in their tombs. My olompotsy informants insisted on the impossibility of cleansing these children. I found this particularly striking because the southern Betsileo make frequent use of rituals to remove various kinds of pollution. Moreover, southern Betsileo rituals for cleansing slaves after manumission are attested in oral histories and archival sources. I was thus interested in knowing whether contemporary southern Betsileo would think that, under some specific conditions, a ritual could cleanse a slave descendant. I made up a story where a young man of slave descent is in love with a free descent girl. Since they cannot marry, the young man decides to ask a ritual specialist to perform a cleansing ritual so that he becomes a clean person.

I have already mentioned the alleged uncleanliness of the slave descendants' blood. I chose to use a blood transfusion story because I knew that when olompotsy create fictive kinship links with slave descendants through a ritual called vakirà they do not drink their blood - as it normally should be for this ritual - but replace it with rum, out of fear of being polluted. Among the southern Betsileo, like in many other cultural contexts (see Carsten 2011), blood ( $r a ̀$ ) is an important symbol. During ceremonies the blood of slaughtered cattle is ritually used to bless, cleanse and protect people as well as material things such as houses. The goal of the blood transfusion task was therefore different from the previous ones since it examined the possibility, for a clean person, to become 'deeply' unclean after receiving blood from an unclean person. In other words, the issue I wanted to explore with this task was one of extremely serious pollution through blood mixing. ${ }^{9}$

Each task had two slightly different versions: the second version (which I call task \#2) was identical to the first version (task \#1) except for one sentence added at the end of the story, which mentioned that local people had reached a consensus with regards to the question under consideration (see the additional sentences in annex IV). This consensus consisted in the view opposite to the one articulated by the majority of respondents in task \#1. The goal was therefore to see whether respondents to task \#2

9 I am grateful to Jonathan Parry for bringing to my attention the issues of blood and uncleanliness in medical contexts. 
would be sensitive to the consensus and significantly change their answers in comparison with the results of task \#1. ${ }^{10}$

All the interviews took place in people's houses. Together with Ramose Martin, a friend who helped me with the implementation of the tasks, we tried to avoid bias in the selection of respondents by choosing randomly a direction everyday (e.g. south) and by walking in this direction from one hamlet to another in search of potential participants. The age of respondents varied from about 20 to about 70 and for each task we kept a balance across gender. All the participants were olompotsy.

The results of the adoption task are given in Figure $1 .^{11}$

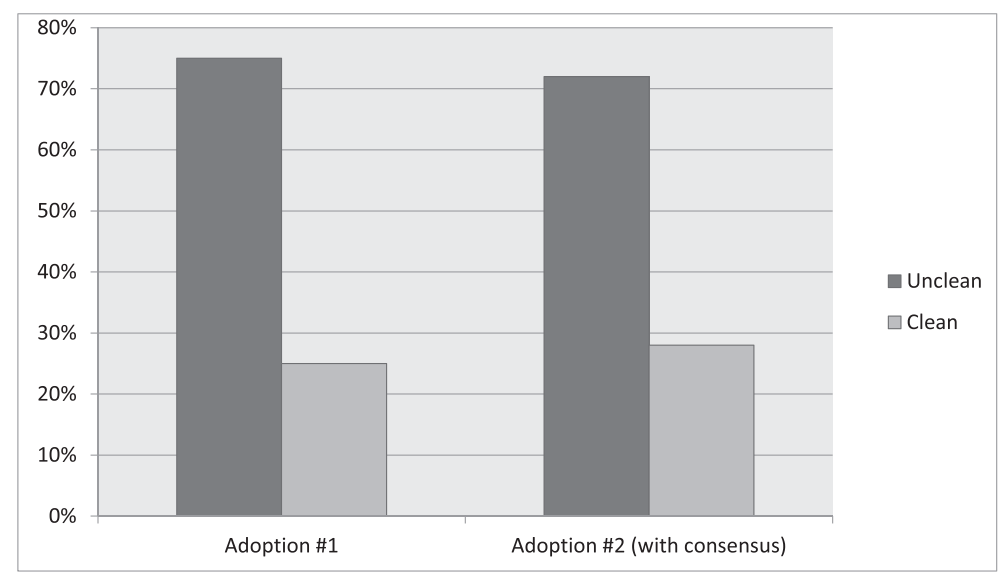

Figure 1 Adoption task

The responses to the first version of the task show that a large proportion (75\%) of the participants judged that an unclean baby raised by a clean couple does not become a clean adult person. In other words, a significant majority thought that the baby could not become clean through adoption by clean parents and long-term affiliation with a free descent group in a free descent village. In the discussion many stressed that 'nothing could be done' for the unclean child. I take this as evidence that most olompotsy essentialise andevo. Some of the respondents who judged that the baby has become a clean adult justified their choice by explaining that the child 'follows the ancestral history (tantarandraza) of his/her [adoptive] parents'. I understand this as meaning that these olompotsy overrode the essentialist construal of 'slaves' that prevailed among their peers and gave more weight to their 'fluid' conceptions of kinship and identity. Others justified their answer by referring to Christian beliefs and stressing that there were no such differences between people.

10 Ideally I should also have run a third version of the task with a consensus that referred to the view of the majority of respondents (i.e. the view opposed to the consensus expressed in the second version of the task), but this was not possible due to time constraints and to the difficulty in finding respondents.

11 All the results are presented in rounded percentages for comparative purposes. For the adoption task we had 24 respondents for the first version (Adoption \#1) and 18 for the second version with the consensus (Adoption \#2). 
Interestingly, the results show that the mention of a consensus on the view that the adopted baby has become a clean adult person has no significant effect on the pattern of the responses. ${ }^{12}$ This apparently suggests that essentialist thinking might be quite impervious to what other people in the village would think. Moreover the similarity with the results obtained with the first version of the task seems to indicate that olompotsy consistently essentialise the andevo.

The cleansing ritual task provided very similar responses and thus also showed that a large proportion of olompotsy essentialise slave descendants (see Figure 2). ${ }^{13}$

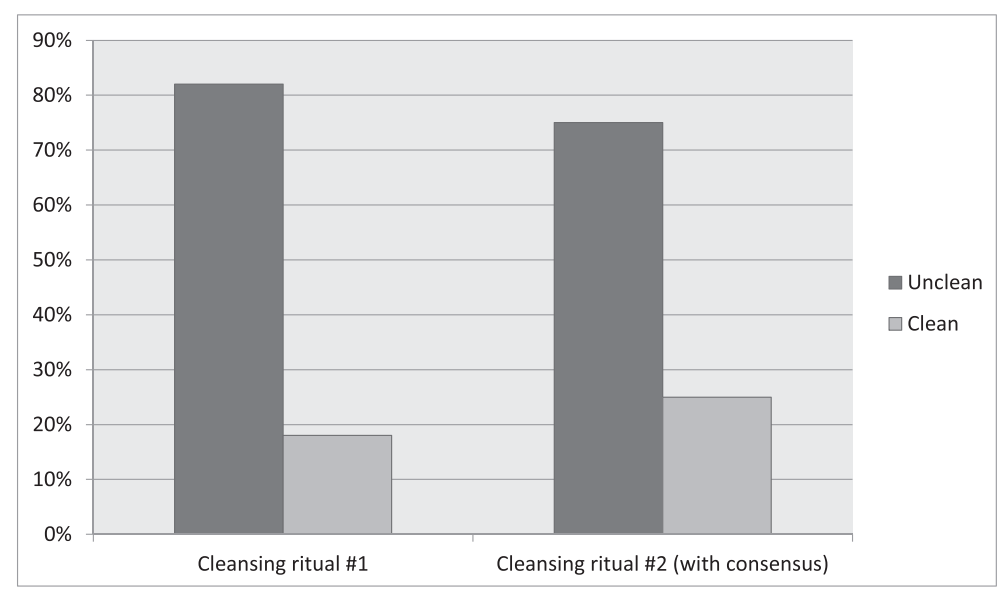

Figure 2 Cleansing ritual task

A large majority of respondents holds that the most powerful cleansing ritual one can think of in the southern Betsileo context (and which was used in the past for cleansing slaves) cannot cleanse present-day slave descendants. Interestingly, during the discussions people stressed that such a cleansing could not be performed successfully today because, they explained, the hova have lost the power they had in the past. The two reasons they gave for this loss was French colonisation, which put the hova's role as rulers to an end, and the hova's intermarriages with olompotsy, which resulted in corrupting 'what makes them hova' (ny maha-hova). These comments were made even though I had anticipated the second reason and mentioned in the script that the ritual specialist was a hova tena hova (hova mbola tsy nanambady vohitse), i.e. a 'noble really noble (nobles who have not yet married commoners)'. ${ }^{14}$

12 For the adoption task, $\chi^{2}(1)=.04$ and $p=.84$. The $p$-value being greater than .05 , we cannot reject the null hypothesis.

13 We had 18 respondents for Cleansing ritual \#1 and 24 for Cleansing ritual \#2.

14 Among the southern Betsileo, healers-diviners (ombiasa), heads of families and hova can perform cleansing rituals. The most powerful ones are believed to be those of hova (provided they have not intermarried with olompotsy), followed by heads of families and then ombiasa. In an early version of the task I made the mistake of using an ombiasa in the story, but my informants advised me to refer to a hova instead, to make sure that the story seemed credible. 
Moreover, like in the previous task, the mention of a consensus did not seem to have any significant effect. ${ }^{15}$

The results for the first version of the blood transfusion task (Figure 3) do not show a clear preference for one response over the other and their interpretation is thus less straightforward. ${ }^{16}$

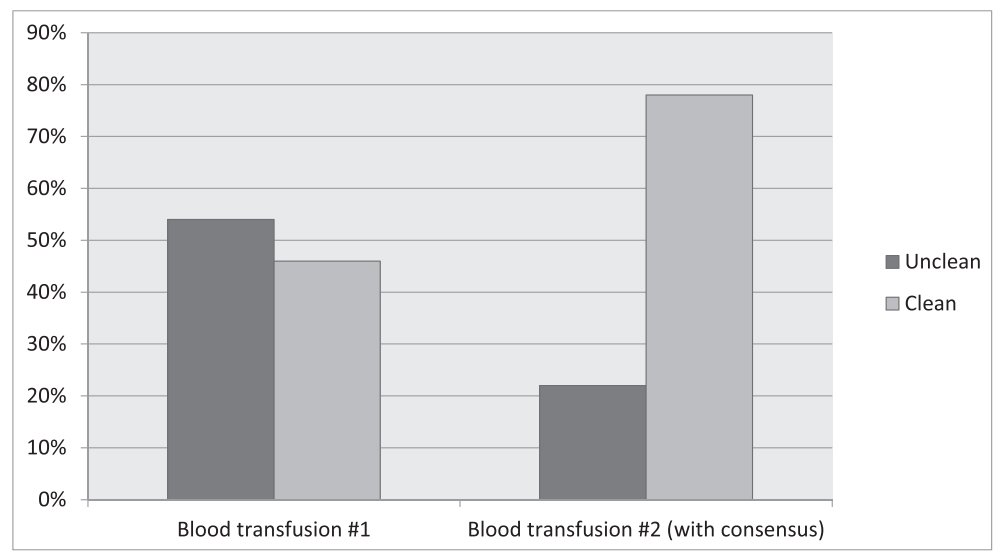

Figure 3 Blood transfusion task

The running of the two versions of the task and the discussions that followed provided interesting insights nonetheless. First, it should be noted that, unlike the other tasks, the blood transfusion story seemed a bit unfamiliar to the participants. They clearly knew about the medical act of transfusing blood, but because the region is far away from the closest hospital and most people in Beparasy have never been hospitalised, the question sounded less familiar than those about adoption, marriage or cleansing ritual. Whereas people understood the other stories as a real possibility and could answer the question quickly, during this task they expressed surprise at the question and took some time before giving their judgement. Moreover, during the discussions it became clear that their responses depended on their interpretation of the task's question. Most of them answered that Rakoto, the character who received blood, has become unclean if they interpreted the question to be about the kind of 'superficial' pollution that I have already mentioned in case of mixed couples and which can be cleansed through a ritual. The other half answered that Rakoto had not become unclean if they interpreted the question to be about Rakoto's transformation into a slave descendant. Therefore, once the answers are put in the context of the discussions that followed the task, it becomes apparent that only a handful of respondents thought that Rakoto had become as unclean as an andevo. Most of them judged instead that Rakoto was only superficially polluted after receiving the unclean blood. They explained that he could be cleansed by a ritual and buried in an ancestral tomb.

Unlike the previous tasks, the mention of a consensus on the view that Rakoto is still clean after the transfusion seemed to have a significant effect. ${ }^{17}$ As I have just

15 For the cleansing ritual task, $\chi^{2}(1)=.04$ and $p=.51$. Here again the $p$-value is greater than .05 so we cannot reject the null hypothesis.

16 We had 24 respondents for Blood transfusion \#1 and 18 for Blood transfusion \#2.

17 For the blood transfusion task, $\chi^{2}(1)=4.36$ and $p=.04$. The $p$-value is less than .05 so we can take the decision to reject the null hypothesis. 
explained, the words 'become unclean' in the task's question could mean either 'become superficially polluted' or 'become deeply polluted' (i.e. become an andevo). I would therefore argue that the difference of results between the two versions of the task means that the respondents were somewhat perplexed about how to interpret my question and therefore most of them followed the consensus mentioned in the second version, while in the first version indecision was predominant. Overall, the results of the tasks suggest that for most respondents receiving unclean blood from a slave descendant does not cause a deep and irreparable pollution. I interpret this as meaning that, in spite of what olompotsy sometimes told me, they do not perceive the alleged unclean blood of slave descendants as the causal factor for their uncleanliness. I would rather argue that the olompotsy tend to conceptualise the 'inner essence' of slave descendants in terms of blood because it is a bodily substance that is particularly 'good to think', to use Lévi-Strauss' famous phrase. As Medin and Ortony argued (1989: 184-5), psychological essentialism is a placeholder notion: one can believe that a category has an essence without knowing exactly what the essence is.

\section{Were slaves already essentialised before abolition?}

The data obtained with the field experiment confirmed what I had inferred from my ethnographic observations, namely that present-day olompotsy essentialise slave descendants. One of the main points that emerged is the extent to which people hold that the slave descendants' unclean status is irredeemable. The conversations with respondents also comforted my intuition that the essentialist construal of andevo needs to be understood in a historical perspective (Regnier 2012: chapter 7). In this section, I would like to argue that before abolition slaves must have been differently conceptualised to how their descendants are today, and to suggest that after abolition a subtle but important conceptual change occurred in the way southern Betsileo olompotsy think of the andevo.

As far as we know, slavery is probably a very ancient institution in Madagascar. It increased in scale, however, with the arrival of Europeans and their need for slave labour in the Indian Ocean (Allen 2014), as well as with the rise of the Merina empire in Madagascar (Campbell 2005). From the end of the 18th century and during most of the 19th century, enslavement became so widespread in the Malagasy highlands that everyone was continuously at risk of being enslaved (Larson 2000). Virtually every individual, noble or commoner, rich or poor, man or woman, adult or child, could be captured and sold, being the victim of a local war, of a raid operated by the bands of 'men's thieves' (mpangalatr'olo) that plagued the highlands until the end of the 19th century, or of ill-intentioned neighbours who wanted to make some money. According to Larson, 'By 1820, perhaps as many as 70 percent of highland Malagasy households experienced the loss of a member to the export slave trade' (1999: 341).

At the same time, in the pre-abolition era, slaves could be freed through a legal process and could rid themselves of the unclean status associated with enslavement through ritual cleansing. Slaves could work in addition to their duties, save money and buy themselves back from their masters (Rakoto 1997). The ubiquity, frequency and the very possibility of these changes of status make it very likely that free people regarded slave status as a contingent rather than a fixed status. People must have conceived enslavement as a shameful yet reversible condition, the uncleanliness of which could be removed if one could do the necessary ritual. In other words, the 
uncleanliness of slaves was probably not viewed as immutable and irredeemable. Furthermore, in pre-abolition times the category of andevo was not necessarily perceived as a 'forced social category'. Oral histories attest that it was frequent to see poor olompotsy propose their own enslavement to the hova because their slaves had better living conditions than the poorest segments of the free peasantry. It is therefore likely that the category andevo was, in pre-abolition times, not perceived as a natural kind as it is today. The category of slaves was probably not perceived as highly entitative either: given the precariousness of their condition and the diversity of their trajectories, andevo were probably viewed more as a collection of individuals than as a coherent group.

I find historical evidence supporting my argument in a document that was only recently discovered in the archives of a Norwegian missionary (Razafindralambo 2008) and translated and published by Gueunier et al. (2005). The published material consists of three texts. In the first, a southern Betsileo man named Isambo of noble origin explains how he was kidnapped as a child in Betsileo country, brought to Antananarivo to be sold on the slave market and then finally bought by Lutherian missionaries who freed him. Isambo became a primary school teacher in Fianarantsoa. In the second text, Isambo tells the story of how, after many difficulties, he managed to contact his relatives in the southern Betsileo region of Ikalamavony, ten years after having been kidnapped. The third part of the document is a manuscript entitled 'The customs to accomplish to "wash the tongue", or to give the blessing to a child who has been rejected but will become a child again' (literal translation of $N y$ fomba fanao raba manoza lela na hanao tsiodrano zaza nariana ka haverina ho zanaka indray). According to the editors, although the manuscript is not signed, it is very likely to have been written by Isambo, as indicated by the resemblance of the handwriting with Isambo's autobiographical accounts mentioned earlier, and by the use of Betsileo dialect in parts of the description (Gueunier et al. 2005: 72-3).

Isambo wrote his account shortly before the abolition of slavery. The ritual of 'washing the tongue' (manoza lela) - a variant of the 'scratching of the tongue' (mikao-dela) that was described to me in Beparasy - is presented as a ritual that could be performed with two different aims: to reintegrate people who had been freed from slavery, or to reintegrate children who had been previously repudiated by their parents. Thus, in both cases, the cleansing ritual serves the purpose of reintegrating an individual into a local descent group and, consequently, into a wider local community of kinsmen.

Isambo's account provides evidence that slaves were indeed considered as dirty and extremely diminished persons (see also Regnier 2014a), because of the inferior tasks they had to perform for their owners, because they had to forgo their own ancestral taboos and because they had to serve other people who should have been their equals or their inferiors. Yet Isambo's detailed description of the ritual also shows beyond doubt that it was always possible to ritually remove the deep uncleanliness associated with enslavement. Indeed, it seems to indicate that, at that time, people thought that these cleansing rituals were all-powerful. As the speech reported by Isambo states, 'there is nothing dirty that [sacred] water cannot remove' (tsy misy maloto tsy bo afaky ny rano). In the description, when the ritual performer put sacred water on the head of the person who needs to be cleansed, he says:

Although you served others who were people like you, although you did what your ancestors did not, although you were subject everyday to the imprecations 
of your master, we cleanse you with this water. However you were soiled, may the misfortune not follow you, may the fault not follow you. We pray for you with this water (...) so that you become 'nicely accomplished' (vita soa), so that you become 'well accomplished' (vita tsara). (Gueunier et al. 2005: 167-8, my translation)

At the end of his account, Isambo comments:

It is when all this has been accomplished that his/her family can count him/her again as one of its members, and that it is allowed to bury him/her in the ancestral tomb. Because as long as this ceremony of 'washing the tongue' has not been performed he/she is not allowed to be buried in the ancestral tomb and he/she cannot marry someone of the same 'kind' (karazana) in the local community. (Gueunier et al. 2005: 168-9, my translation)

Isambo's description of the ritual of manoza lela shows that free southern Betsileo did not think of slaves as people who could not fully regain their free and clean status once they had lost it. To my knowledge, there is no historical evidence that a strong stigma or taint comparable to that of today's slave descendants was attached to having been a slave during part of one's life or to having ancestors who had been enslaved. As indicated by Isambo, former slaves were considered as suitable marriage partners by the 'clean' local community as soon as they had performed the cleansing ritual and had been reintegrated into their descent group. I would therefore assume that provided they went through the appropriate ritual any kind of formerly enslaved persons were completely redeemed, did not suffer from any prejudice and discrimination because of their personal history and did not 'transmit' any uncleanliness to their children. If so, this means that the crucial features of the essentialism observed today were absent.

\section{Essentialism as a consequence of the colonial abolition}

If I am right, the essentialist construal became entrenched only after the colonial abolition of slavery. An important shift seems to have taken place - but why? I suggest that the explanation for such a shift is to be found in the context of the abolition. To understand why this event might have significantly modified the way southern Betsileo people think about slaves, former slaves and their descendants, it is necessary to go back to its circumstances and most immediate consequences.

On 30 September 1895, a French expeditionary force entered Antananarivo. The military takeover was soon followed by the annexation of Madagascar on 6 August 1896. On 27 September 1896, only one year after the French troops had reached Antananarivo, slavery was abolished and hundreds of thousands of slaves - perhaps as many as 500,000 according to some authors - were set free in a total population of about three million Malagasy (Campbell 2005: 136). The resident governor Laroche had decreed the abolition just before leaving his office to his successor General Gallieni, 'in a fit of pique' (Randrianja and Ellis 2009: 157).

The question of whether the French administration should immediately emancipate the slaves or adopt a more careful approach, abolishing slavery step by step, had been discussed in the French parliament in June 1896. The context was particularly difficult, since the French occupiers faced an anticolonial rebellion. Opponents to an immediate abolition feared an increase in social disorder that could damage French 
interests in Madagascar (Jacob 1997: 262). In spite of these concerns, the parliament unanimously voted in favour of an immediate abolition. Up to this point, resident governor Laroche had worked on a plan to abolish slavery progressively over the course of ten years, but when the minister of the colonies asked him to examine how to execute the will of the parliament, he replied: 'I am ready to abolish slavery whenever you want.' A few days later, he added: 'The best would be to rush the decision. We should not fear troubling what is already troubled. Abolition will pass unnoticed (or less noticed) during the insurrection' (quoted in Jacob 1997: 265, my translation). Laroche then convened a committee in Antananarivo to work on a draft of the decree. In this committee, anxious voices were again heard about the unpredictable consequences of an immediate abolition. Yet, once again, the vote decided on immediate abolition. On 26 September, Laroche received a message from the Ministère des Colonies requesting that he follow the decision of the committee and that he abolish slavery immediately. He signed the decree on the same day and published it in the Journal Officiel de Madagascar the day after. On 28 September, Laroche handed over his power to Gallieni.

To the satisfaction of many, including that of Gallieni - who was opposed to the immediate abolition - the emancipation of slaves in 1896 did not lead to a social disorder prejudicial to French interests. But what was the effect of the abolition on Malagasy society? Did it provoke a social change of great magnitude? Three years later, Jean Carol, a French official, wrote that it 'hasn't changed anything to the customs of the Malagasy so far' (Carol 1898: 30, my translation). Scholars have tended to endorse this view, stressing in particular that traditional hierarchy and the rules governing relations between status groups, including those related to marriages, have continued to be observed as if nothing happened (e.g. Rantoandro 1997: 283). Unlike these authors, I want to argue that, for the southern Betsileo at least, the abolition caused an important change in the way people conceived of slaves and their descendants.

After abolition, those who had been recently enslaved went back to their region. We can assume that most were welcomed by their kinsmen and ritually cleansed by their elders in the way described by Isambo. They could resume the life of a free man or woman, and most probably did not suffer from stigmatisation because of their former enslavement. They were able to find a 'clean' spouse and to have offspring who found their place in the ancestral tombs. However, a large number of slaves whose forebears had been born into slavery for several generations had been severed from the links with their descent groups and after their liberation they were unable to go back to a region where they could be reintegrated into a kin group. ${ }^{18}$ In the aftermath of the abolition, there must have been a large number former slaves moving around, who could not identify with a tanindrazana (ancestral land) other than that of their former masters. But if they did not want to stay on their former masters' estates on a sharecropping arrangement they had no place to establish themselves.

Some, like the Berosaiña in Beparasy, found free land to cultivate in remote places, but because their liberation was decided and imposed by the illegitimate power of French colonisers, southern Betsileo olompotsy continued to perceive them as people

18 It should be noted that my account is mainly concerned with the case of 'internal' slaves (i.e. 'indigenous' slaves), as opposed to that of slaves who were acquired in continental Africa and are called Makoa in several parts of the island (see Boyer-Rossol 2013). To my knowledge there are no Makoa in the southern Betsileo region, where people think that the andevo are all of Malagasy origin. 
who had not been properly freed according to custom and had remained unclean. As explained above, before abolition it was crucial for the southern Betsileo to ritually cleanse former slaves so that they could reintegrate into their kin group and, through it, into local society as a whole. The 1896 French decree, by contrast, did not meet the minimal conditions to be considered by the southern Betsileo as a proper cleansing.

In other words, slaves were liberated by a colonial authority that had nothing of the traditional powers that could have freed them through an appropriate administrative procedure and cleansed them through an appropriate ritual. Among the southern Betsileo, the local conception of enslavement as a deeply polluting condition led people to think that the former slaves who had not been reintegrated into one of their descent groups were still 'unclean people'. It is therefore in light of the sudden liberation, by the colonial government, of a large number of slaves who could not be properly cleansed that the essentialisation of the andevo must be understood.

In the introduction I mentioned the 'vicious circle' in which the Berosaina of Beparasy are stuck: since olompotsy strictly avoid marrying them they have no other choice than marrying other unclean people, and by so doing they reinforce the olompotsy's prejudice against them. Such a circular process of marriage avoidance and prejudice reinforcement must have been going on since the aftermath of the abolition and played a leading role in driving and fuelling the essentialisation of slave descendants as a natural kind. Given that the southern Betsileo have a strict rule of status isogamy one should only marry people of equal status - after abolition the olompotsy families became extremely vigilant and put much effort into avoiding any marriage with people they regarded as unclean. These efforts included carefully checking the 'origins' of their marriage partners and imposing strong social sanctions against the group members who breached the prohibition (Regnier 2014b).

\section{Conclusion}

In this article I have sought to combine ethnographic, cognitive and historical perspectives to provide an account of the essentialisation of 'slaves'. If my account is right, then it is the acute problem posed by the uncleanliness of freed slaves in the aftermath of the abolition that triggered the historical process of essentialisation. Among the southern Betsileo, this process led to the binary distinction between unclean and clean people that has now supplanted, in importance, the old division in three status groups, although the distinction between raza still remains meaningful. My views on this matter sharply contrast with the idea, commonly accepted, that the contemporary discrimination against the andevo is 'simply' a legacy of the ancient hierarchical system. This does not seem to be the case and it is a strange paradox that the colonial abolition of 1896 might be partly the cause of the awkward predicament in which southern Betsileo slave descendants find themselves today.

\section{Acknowledgements}

The initial fieldwork in highland Madagascar (2008-2010) was conducted for my $\mathrm{PhD}$ at the London School of Economics (LSE), with funding from the LSE, the University of London and the Wenner-Gren Foundation. I designed the cognitive tasks, implemented them in Madagascar and wrote this article while I was a 
Postdoctoral Research Fellow on the ERC-funded project DIVIDNORM (ERC 269616) at the École Normale Supérieure (Institut Jean Nicod) in Paris, and a Scientific Collaborator at the Laboratoire d'Anthropologie des Mondes Contemporains (Université Libre de Bruxelles). At different stages of my research I greatly benefited from discussions with Rita Astuti, Maurice Bloch, Fabrice Clément, Michael Lambek, Laurent Licata, Jonathan Parry and Dominique Somda. Two anonymous reviewers provided insightful comments on the manuscript. I am deeply grateful to all these institutions and persons. I am also indebted to Ramose Martin for his help and to all the villagers in Beparasy for allowing me to take part in their lives.

Denis Regnier

Laboratoire d'Anthropologie des Mondes Contemporains (LAMC)

Institut de Sociologie - Université Libre de Bruxelles

Avenue Jeanne 44, 1050 Bruxelles Belgium

dregnier@ulb.ac.be

\section{References}

Allen, R. 2014. European slave trading in the Indian Ocean, 1500-1850. Athens, OH: Ohio University Press.

Astuti, R., G. Solomon and S. Carey 2004. 'Constraints on conceptual development: a case study in the acquisition of folkbiological and folksociological knowledge in Madagascar', Monographs of the Society for Research in Child Development 69(3): 1-135.

Atran, S. 1998. 'Folk biology and the anthropology of science: cognitive universals and cultural particulars', Behavioral E Brain Sciences 21: 547-609.

Bloch, M. 1993. 'Zafimaniry birth and kinship theory', Social Anthropology 1(1b): 119-32.

Bloch, M., G. Solomon and S. Carey 2001. 'Zafimaniry: an understanding of what is passed on from parents to children: a cross-cultural investigation', Journal of Cognition and Culture 1(1): 43-68.

Boyer-Rossol, K. 2013. Makua life histories: testimonies on slavery and the slave trade in the 19th century in Madagascar, in A. Bellagamba, S. Greene and M. Klein (eds.), African voices on slavery and the slave trade, volume 1: the sources, 466-80. Cambridge: Cambridge University Press.

Campbell, G. 2005. An economic history of imperial Madagascar, 1750-1895: the rise and fall of an island empire. Cambridge: Cambridge University Press.

Carol, J. 1898. Chez les Hova (au pays rouge). Paris: Ollendorff.

Carsten, J. 2011. 'Substance and relationality: blood in contexts', Annual Review of Anthropology 40: 19-35.

Demoulin, S., J.-P. Leyens and V. Yzerbyt 2006. 'Lay theories of essentialism', Group Processes E Intergroup Relations 9(1): 25-42.

Evers, S. 2002. Constructing history, culture and inequality: the Betsileo in the extreme southern highlands of Madagascar. Leiden: Brill.

Freeman, L. 2013. 'Speech, silence, and slave descent in highland Madagascar', Journal of the Royal Anthropological Institute 19: 600-17.

Gelman, S. 2003. The essential child: origins of essentialism in everyday thought. Oxford: Oxford University Press.

Gil-White, F. 2001. 'Are ethnic groups biological species to the human brain? Essentialism in our cognition of some social categories', Current Anthropology 42: 515-45.

Gueunier, N., F. Noiret and S. Raharinjanahary 2005. Esclavage et liberté sur les Hautes Terres à la fin du XIXe siècle: l'histoire de l'asservissement et de la rédemption d'Isambo, ou Aogosta Herman Franke, 1877-1893, d'après les manuscrits Walen, in C. Ratongavao (ed.), Hommage à Bruno Hübsch, volume II, 69-178. Lyon: Profac. 
Harris, M. and C. Kottak 1963. 'The structural significance of Brazilian racial categories', Sociologica 25: 203-9.

Hirschfeld, L. 1996. Race in the making: cognition, culture, and the child's construction of human kinds. Cambridge, MA: MIT Press.

Jacob, G. 1997. L'abolition de l'esclavage. Madagascar: les perspectives françaises, in I. Rakoto (ed.), L'esclavage à Madagascar: aspects historiques et résurgences contemporaines, 259-71. Antananarivo: Institut de Civilisations - Musée d'Art et d'Archéologie.

Kottak, C. 1980. The past in the present: history, ecology, and variation in highland Madagascar. Ann Arbor, MI: University of Michigan Press.

Kottak, C. 1986. Kinship modeling: adoption, fosterage, and fictive kinship among the Betsileo, in C. Kottak, J.-A. Rakotoarisoa, A. Southall and P. Vérin (eds.), Madagascar: society and history, 277-98. Durham, NC: Carolina Academic Press.

Larson, P. 1999. 'Reconsidering trauma, identity, and the African diaspora: enslavement and historical memory in nineteenth-century highland Madagascar', The William and Mary Quarterly 56(2): 335-62.

Larson, P. 2000. History and memory in the age of enslavement: becoming Merina in Highland Madagascar, 1770-1822. Oxford: James Currey.

Mahalingam, R. 1998. Essentialism, power and representation of caste: a developmental study. Unpublished $\mathrm{PhD}$ thesis, University of Pittsburgh.

McIntosh, J. 2005. 'Language essentialism and social hierarchies among Giriama and Swahili', Journal of Pragmatics 37(12): 1919-44.

Medin, D. 1989. 'Concepts and conceptual structure', American Psychologist 44: 1469-81.

Medin, D. and A. Ortony 1989. Psychological essentialism, in S. Vosniadou and A. Ortony (eds.), Similarity and analogical reasoning, 179-95. Cambridge: Cambridge University Press.

Prentice, D. and D. Miller 2007. 'Psychological essentialism of human categories', Current Directions in Psychological Science 16(4): 202-6.

Rakoto, I. (ed.) 1997. L'esclavage à Madagascar: aspects historiques et résurgences contemporaines. Antananarivo: Institut de Civilisations - Musée d'Art et d'Archéologie.

Randrianja, S. and S. Ellis 2009. Madagascar: a short history. Chicago, IL: Chicago University Press.

Rantoandro, G. 1997. Après l'abolition de l'esclavage à Madagascar: le devenir immédiat des esclaves émancipés, in I. Rakoto (ed.), L'esclavage à Madagascar: aspects historiques et résurgences contemporaines, 273-88. Antananarivo: Institut de Civilisations - Musée d'Art et d'Archéologie.

Razafindralambo, L. 2014. Esclavage et inégalités. Entre constructions sociales et différences 'naturelles', in I. Rakoto and S. Urfer (eds.), Esclavage et libération à Madagascar. Paris: Karthala.

Regnier, D. 2012. Why not marry them? History, essentialism and the condition of slave descendants among the southern Betsileo (Madagascar). Unpublished $\mathrm{PhD}$ thesis, The London School of Economics and Political Science.

Regnier, D. 2014a. 'Les esclaves morts et leur invocation dans les rituels du Sud Betsileo', Études Océan Indien 51-52: 253-76.

Regnier, D. 2014b. 'Pourquoi ne pas les épouser? L'évitement du mariage avec les descendants d'esclaves dans le Sud Betsileo (Madagascar)', Études Rurales 194: 103-22.

Rothbart, M. and M. Taylor 1992. Category labels and social reality: do we view social categories as natural kinds? in G. Semin and K. Fiedler (eds.), Language, interaction and social cognition, 11-36. Thousand Oaks, CA: Sage.

Somda, D. 2009. Et le reel serait passé: le secret de l'esclavage et l'imagination de la société (Anôsy, sud de Madagascar). Unpublished PhD thesis. Université Paris Ouest Nanterre La Défense.

Southall, A. 1986. Common themes in Malagasy culture, in C. Kottak, J.-A. Rakotoarisoa, A. Southall and P. Vérin (eds.), Madagascar: society and history, 411-26. Durham, NC: Carolina Academic Press.

Yzerbyt, V., O. Corneille and C. Estrada 2001. 'The interplay of subjective essentialism and entitativity in the formation of stereotypes', Personality and Social Psychology Review 5(2): 141-55.

Yzerbyt, V., C. Judd and O. Corneille 2004. The psychology of group perception: perceived variability, entativity, and essentialism. New York: Psychology Press. 


\section{Annexes}

\section{Annex I. Adoption story}

Marcel and Hanitra are Betsileo. They come from a clean family. They have been married for a long time but they did not conceive children. One day, Marcel found a baby abandoned in the forest. Marcel and Hanitra were happy to adopt the baby and they raised it until adulthood. The truth, however, is that the baby is the child of unclean people who abandoned it in the forest because of poverty.

Question: In your opinion, when it reaches adulthood, is the child still an unclean person or has it become a clean person?

\section{Annex II. Cleansing ritual}

Mamy and Vao are Betsileo and live in the same village. They love each other but cannot marry because Mamy comes from an unclean family and Vao from a clean family. Mamy goes to see a noble 'really noble' (i.e. nobles who have not yet married commoners) and he asks him to perform a cleansing ritual so that he becomes a clean person and can marry Vao. The noble accepts. Mamy is bathed with water that contains silver and hazomanga [i.e. sacred wood], a zebu is slaughtered, its blood is put on Mamy's forehead and the traditional speeches are made.

Question: In your opinion, after the cleansing, is Mamy still an unclean person or has he become a clean person?

\section{Annex III. Blood transfusion}

Rakoto is Betsileo. He comes from a clean family that lives close to Fianarantsoa. One day he takes a bush-taxi to go to the city. An accident occurs on the road and he is seriously injured. He is brought to the hospital of Tambohobe [i.e. the hospital in Fianarantsoa]. He needs a blood transfusion since he has lost too much blood. For this transfusion, the doctors use the blood of Ralaza, a man from an unclean family.

Question: In your opinion, after the transfusion, is Rakoto still clean or has he become unclean?

\section{Annex IV. Additional sentences with reference to a consensus}

At the end of the adoption story:

All the villagers agree that the baby has become a clean person because it was raised by clean parents.

At the end of the cleansing ritual story:

All the villagers agree that Mamy has become a clean person because he was cleansed by a hova tena hova.

At the end of the blood transfusion story:

All the villagers have learnt that Rakoto has received the blood of a slave descendant but they all agree that he is still a clean person. 